\title{
Um estudo sobre a adoção de práticas de gestão do conhecimento em organizações cooperativas
}

\author{
Luciano Czermainski Gonçalves PUCPR \\ Edson Pinheiro de Lima PUCPR \\ Sérgio Eduardo Gouvêa da Costa PUCPR
}

\section{RESUMO}

As organizações vêm desenvolvendo um profundo processo de mudança na maneira como concebem e realizam as suas estratégias de negócio. Particular atenção vem sendo dada à gestão do conhecimento, em função do valor estratégico que este recurso pode assumir. Este artigo apresenta os resultados de uma pesquisa cujo objetivo é determinar o posicionamento de um conjunto de organizações cooperativas em relação à adoção de práticas de gestão do conhecimento. São apresentados os resultados de cinco estudos de caso em um universo de vinte e duas unidades de negócio de cooperativas do Sudoeste do Paraná. O estudo apresenta o desenvolvimento e o teste de um procedimento de análise denominado 'Matriz de Adoção'. Dos resultados, identificam-se a presença de funções e práticas de gestão do conhecimento em todas as organizações cooperativas estudadas, sendo que, em sua ampla maioria, incompletas no que se refere à implantação de um modelo de gestão do conhecimento.

\section{PALAVRAS-CHAVE}

Modelos de gestão do conhecimento, funções de gestão do conhecimento, práticas de gestão do conhecimento, organizações cooperativas.

\section{Knowledge management practices study in cooperatives organisations}

\begin{abstract}
Organisations are developing an in-dept change process on how they design and implement their business strategies. A special attention is given to knowledge management, as they recognize the potential strategic value that this resource could have. This paper presents the results of a research project, which main goal is to identify and represent the positioning of a set of cooperative organizations related to the adoption of knowledge practices. The results of five case studies are presented; they are defined in a universe of twenty two cooperatives business units in Parana South East region. The study presents the development and test of an analysis procedure named 'Adoption Matrix'. Based on results, it is identified the knowledge management functions and practices presence, however, they are incomplete in the sense of a knowledge management model implementation.
\end{abstract}

\section{KEY WORDS}

Knowledge management models, knowledge management functions, knowledge management practices, cooperative organisations. 


\section{INTRODUÇÃO}

Estudos a respeito da compreensão do processo de criação de valor nas organizações têm recebido uma atenção especial na agenda das empresas, como também no meio acadêmico, especificamente pesquisas que procuram estabelecer uma relação de causalidade entre estratégia empresarial, gestão do conhecimento e desempenho (CHOI et al., 2007; MARQUÉS; SIMÓN, 2006; HALAWI et al.,2006)

Barney (1991) identifica nos recursos gerenciados por uma empresa a base para o desenvolvimento da sua estratégia de negócios. Particularmente, a mobilização destes recursos cria capacitações que integradas aos processos de negócios desenvolvem as competências que explicam a criação de valor em um empreendimento. Nonaka e Takeuchi (1997) atribuem à base de conhecimento um valor estratégico, sendo este 'recurso' o substrato para a criação de capacitações e o desenvolvimento de competências.
$\mathrm{O}$ artigo inicialmente apresenta uma discussão acerca de sistemas, modelos, funções, processos e práticas relacionados à gestão do conhecimento, para então desenvolver um protocolo de pesquisa e investigar o posicionamento do conjunto selecionado de organizações cooperativas em relação à adoção de práticas de gestão do conhecimento.

\section{DEFININDO FUNÇõES PARA A GESTÃO DO CONHECIMENTO}

As organizações podem assumir diferentes representações e, segundo Meyer e Sugiyama (2007) e Morgan (1995), podem assumir funções cognitivas. Nesta perspectiva a organização pode desenvolver competências relacionadas à aprendizagem, possibilitando o engajamento das mesmas em ciclos evolutivos. Este tipo de representação social caracteriza as organizações da Era do Conhecimento.

Kjærgaard e Kautz (2008),

\section{$A \begin{aligned} & \text { s relações que se estabelecem entre organização e } \\ & \text { conhecimento devem ser estudadas na sua dimensão }\end{aligned}$ social e na perspectiva de sua aplicação prática.} Halawi et al. (2006) e Pádua et al. (2004) estabelecem as bases para o desenvolvimento de um modelo organizacional que promove uma integração entre estratégia e processos, bem como estabelecem mecanismos

Novos modelos de gestão vêm sendo concebidos buscando desenvolver o alinhamento estratégico da gestão do conhecimento, bem como a infra-estrutura necessária para os processos de gestão. Adotam uma abordagem sistêmica para a gestão do conhecimento, desenvolvem a sua componente estratégica, utilizam as tecnologias de informação e comunicação como recursos de infra-estrutura e avaliam o desempenho das ações desenvolvidas (JUNG et al., 2007; YEH et al., 2006; CHAE; BLOODGOOD, 2006; PINHEIRO DE LIMA et al., 2005; PEREIRA, 2003; LEE; HONG, 2002).

O presente trabalho apresenta um estudo a respeito da adoção de práticas de gestão do conhecimento em organizações cooperativas do Sudoeste do Estado do Paraná. Tal pesquisa visa identificar o grau de desenvolvimento dos sistemas de gestão do conhecimento, avaliando o posicionamento destas organizações em relação à adoção de práticas de gestão do conhecimento que, por sua vez, materializam a realização de um conjunto integrado de funções para a gestão do conhecimento.

A pesquisa desenvolvida tem caráter exploratório e utiliza uma abordagem qualitativa baseada em estudos de caso. Foram estudadas cinco organizações cooperativas no Sudoeste do Paraná. para captura e representação de forma estruturada do 'conhecimento organizacional' e do 'negócio'. Destaca-se a inclusão do conhecimento nos projetos de revisão da estrutura e dos processos organizacionais.

King (2003) conceitua a organização que faz uso efetivo do conhecimento organizacional (Effective knowledge organization - EKO) como uma organização que cria, explica e comunica o conhecimento e o aplica para desenvolver melhores processos de tomada de decisão e comportamentos organizacionais que influenciam positivamente o desempenho global da empresa.

Augier e Knudsen (2004) estabelecem que a arquitetura e o projeto organizacional das 'organizações do conhecimento' devem estar orientados ao tratamento dos problemas associados à racionalidade limitada e à exposição excessiva aos fluxos de informação. Para Brown e Duguid (2001), as relações que se estabelecem entre organização e conhecimento devem ser estudadas na sua dimensão social e na perspectiva de sua aplicação prática.

A Figura 1 apresenta uma taxonomia para os modelos organizacionais baseados em conhecimento. Dos modelos apresentados, observa-se que a Gestão do Conhecimento pode incorporar os seguintes componentes: processos de negócio, tecnologias de informação, repositórios de conhe- 
cimento e comportamentos individuais (KAKABADSE et al., 2003).

Segundo Canongia et al. (2004), verifica-se a emergência das práticas de gestão do conhecimento no momento em que há um deslocamento do eixo de produção de setores industriais tradicionais, no qual se encontram os setores intensivos em mão-de-obra, matéria-prima e maquinaria, migrando para setores cujos produtos e/ou processos são representados pelo uso intensivo de tecnologias de informação e conhecimento.

Nesta nova abordagem de gestão, o conhecimento é reconhecido como um recurso a ser gerenciado. Para Canongia et al. (2004) "a gestão do conhecimento pode ser sintetizada como um processo articulado e intencional, destinado a sustentar ou a promover o desempenho global de uma organização, tendo como base a criação e a circulação de conhecimento". Para Dawson (2000), a competência em coordenar o uso do recurso conhecimento está no centro da eficácia das organizações.

Fundamentado nos trabalhos de Nadler et al. (1994) e de Terra (1999), Santos et al. (2001, p. 34) desenvolvem um modelo organizacional para a gestão do conhecimento. A Figura 2 apresenta o modelo desenvolvido, em que se destacam a abordagem por processo dada à gestão do conhecimento e o seu relacionamento com funções e práticas de gestão do conhecimento. Tal modelo constitui o referencial teórico adotado na construção do protocolo de pesquisa e pode ser considerado, de acordo com a tipologia de Kakabadse et al. (2003), um Modelo Cognitivo para Gestão do Conhecimento.

Para que se desenvolva um processo efetivo de gestão do conhecimento, Kim et al. (2003), Gupta et al. (2000), Beckman (1999) e Davenport e Prusak (1998) relacionam as seguintes funções de gestão do conhecimento: criar, capturar, organizar, codificar, disseminar, avaliar e mensurar.

Uma das funções básicas no processo de gestão do conhecimento é a criação de conhecimento. Sobre essa função, Pereira (2003) informa que esse processo envolve diferentes práticas, tais como a aprendizagem, a 'externalização' do conhecimento, o uso de lições aprendidas, o desenvolvimento do pensamento criativo, da pesquisa e experimentação, da descoberta e inovação. Elenca como as principais fontes para criação de novos conhecimentos a autoaprendizagem, a aprendizagem por meio de especialistas, as relações com clientes, fornecedores e concorrentes, a aprendizagem por experimentação e a adoção do pensamento sistêmico e criativo.

Ao desenvolvimento do conhecimento Probst et al. (2002, p. 34) destacam:

O desenvolvimento do conhecimento é um elemento construtivo que complementa a aquisição de conhecimento. Seu foco está na geração de novas habilidades, novos produtos, ideias melhores e processos mais eficientes. O desenvolvimento do conhecimento inclui todos os esforços administrativos conscientemente direcionados para produzir capacidades que ainda não se encontram presentes na organização, ou que ainda não existem dentro nem fora delas.

As organizações utilizam diferentes técnicas para construir seu conhecimento e, por conseguinte, aumentar o valor agregado em seus produtos e processos. Ekstedt (1988) rela-

Modelo Quântico para Gestão do

Conhecimento (Quantum Mode)

\begin{tabular}{|c|c|c|}
\hline \multirow{3}{*}{ 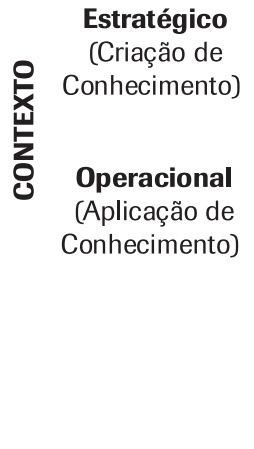 } & $\begin{array}{l}\text { Modelo de Rede para } \\
\text { Gestão do } \\
\text { Conhecimento }\end{array}$ & $\begin{array}{c}\text { Modelo de base Filosófica } \\
\text { para Gestão do } \\
\text { Conhecimento }\end{array}$ \\
\hline & $\begin{array}{l}\text { Modelo Cognitivo } \\
\text { para Gestão do } \\
\text { Conhecimento }\end{array}$ & $\begin{array}{l}\text { Modelo baseado em } \\
\text { Comunidades para } \\
\text { Gestão do Conhecimento }\end{array}$ \\
\hline & $\begin{array}{c}\text { Integrativo } \\
\text { (Orientado a TI) }\end{array}$ & $\begin{array}{c}\text { Interativo } \\
\text { (Orientado a pessoas) }\end{array}$ \\
\hline
\end{tabular}

ABORDAGEM

Figura 1: Modelos de gestão para o conhecimento organizacional.

Fonte: Kakabadse et al. (2003) 
ciona as seguintes ações para a criação de conhecimento:

- Pesquisa e desenvolvimento;

- Atendimento às necessidades de mercados e consumidores implica no contínuo desenvolvimento de produtos, aquisição de tecnologia, educação continuada e recrutamento;

- Educação corporativa (e.g. treinamento).

Pereira (2003) define o processo de captura como a aquisição de conhecimentos, habilidades e experiências necessárias para criar e manter as competências essenciais e áreas de conhecimento selecionadas e mapeadas, de modo que possam ser adequadamente utilizados; esses conhecimentos, habilidades e experiências devem ser formalizados, explicitados e codificados. "Nesse sentido, é importante conhecer as diversas fontes disponíveis (internas e externas), de onde se pode efetivamente adquirir o conhecimento."

De acordo com Probst et al. (2002, p. 35), a retenção do conhecimento requer mais do que apenas adquiri-lo, em virtude de que, uma vez adquiridas, as competências não ficam disponíveis indefinidamente. A gestão, especialmente, deve nortear a retenção seletiva de informações, de documentos e de experiências. É preciso que a organização estruture com cuidado os processos que deverão selecionar, armazenar e atualizar com regularidade um conhecimento com potencial valor futuro, sob o risco de perder-se uma competência valiosa, pois "A retenção do conhecimento depende do uso eficiente de uma grande variedade de meios de armazenagem da organização".

A preservação do conhecimento constitui parte importante da gestão do conhecimento; deste modo, ainda que as empresas se reorganizem, o valor da memória organizacional pode ser subestimado e, muitas vezes, as experiências passadas da empresa não são armazenadas, perdendo-se informações relevantes de sua história. Se o desenvolvimento do conhecimento de uma organização depende, em parte, das bases fornecidas pelo conhecimento anterior, as organizações que desejarem administrar seu conhecimento de modo a que esteja disponível e acessível futuramente, deverão selecionar dentre muitos eventos, pessoas e processos, aqueles que devem ser retidos. Ainda, devem ser capazes de armazenar suas experiências adequadamente, garantindo que a memória organizacional esteja atualizada e preservada (PROBST et al., 2002, p. 175).



Figura 2: Modelo de referência para a gestão do conhecimento.

Fonte: adaptado de Santos et al. (2001, p. 34) 
Na organização do conhecimento, o objetivo é a garantia da recuperação rápida, fácil e correta do conhecimento, por meio da utilização de sistemas de armazenagem efetivos. Pereira (2003) destaca que "quanto mais o conhecimento for formalizado (conhecimento explícito), mais eficaz será o processo de organização e armazenagem".

De acordo com Almeida et al. (2006), ainda que a troca de conhecimento não possa ser confirmada como um processo comum e regular nas empresas, "o processo de codificar e transmitir conhecimentos já é uma tradição". Essa afirmação leva em conta exemplos como programas de treinamentos e desenvolvimento, políticas organizacionais, relatórios e manuais.

Para Smith (2004), a estratégia de gestão do conhecimento deve refletir a estratégia competitiva da empresa. Os esforços para codificação do conhecimento caracterizam a orientação central das estratégias de gestão do conhecimento. Fundamentam-se no intensivo uso das tecnologias de informação e comunicação e promovem substanciais ganhos de produtividade e de satisfação de seus usuários.

Sobre a importância das tecnologias de informação, Tsai (2007) e Almeida et al. (2006) argumentam que elas são vistas como potencial moderno da área da gestão do conhecimento, pelo fato de permitirem que o conhecimento de uma pessoa seja extraído, estruturado e utilizado pelos membros da organização e mesmo pelos seus parceiros de negócios, em nível global. "A tecnologia ajuda também na codificação do conhecimento e, ocasionalmente, até mesmo em sua geração".

Segundo Probst et al. (2002, p. 34), o compartilhamento e a distribuição do conhecimento em uma organização consistem de uma condição imprescindível para transformar informações ou experiências isoladas em um ativo que a empresa possa utilizar. A função de disseminar o conhecimento pode ser trabalhada através de tecnologias de informação.

De modo significativo, o compartilhamento de informação consiste em repassar às pessoas, ou obter delas, algum conjunto de dados com valor econômico variável. Já compartilhar o conhecimento se constitui em algo bem diferente, ocorrendo mediante interesse das pessoas em ajudar umas às outras a desenvolver novas capacitações para a ação e em criar processos de aprendizagem (SILVA, 2002).

Segundo Beckman (1999) é possível que muitas informações e conhecimentos fiquem restritos a grupos pequenos de indivíduos; também é possível que, quando disponibilizados, podem estar ultrapassados ou em local inapropriado. Assim,
"A facilidade de acesso torna-se ponto crítico do processo de compartilhamento e o papel da tecnologia da informação e comunicação é incontestável para tornar o conhecimento disponível, em qualquer tempo e lugar".

Probst et al. (2002, p. 35) apontam como elementos fundamentais na prática da gestão do conhecimento a definição de um conjunto de objetivos e o desenvolvimento de um processo de avaliação. O primeiro diz respeito ao esclarecimento da orientação estratégica da gestão do conhecimento e aos objetivos desdobrados em ações específicas. Quanto ao processo de avaliação, este completa o sistema, ao fornecer dados essenciais para o controle estratégico de projetos de gestão do conhecimento.

De acordo com Choi et al. (2008), Marqués e Simón (2006) e Pinheiro de Lima et al. (2005), o processo de gestão estratégica do conhecimento requer o desenvolvimento de um conjunto de ferramentas para o planejamento e avaliação dos resultados ou do desempenho da gestão do conhecimento.

\section{desenvolvimento do conhecimento inclui todos os esforços administrativos conscientemente direcionados para produzir capacidades.}

Para avaliar, entretanto, são necessários métodos que mensurem o conhecimento normativo, estratégico e operacional. Assim, "A forma em que as metas de conhecimento são formuladas determina as maneiras pelas quais podem ser avaliadas. A qualidade das metas, portanto, torna-se aparente no estágio de avaliação" (PROBST et al., 2002, p. 36).

Quanto à mensuração, Del Rey Chamorro et al. (2003) afirmam que é preciso criar indicadores-chave de desempenho para a gestão do conhecimento no sentido de medir o desempenho da solução implementada e monitorar a adequação da solução adotada aos objetivos estratégicos de negócio.

O processo de avaliação do conhecimento tem duas fases: na primeira, as mudanças na base do conhecimento organizacional devem tornar-se visíveis; na segunda, essas mudanças sofrem interpretação com relação às metas de conhecimento. Avaliar o conhecimento não contempla calcular seu valor monetário, mas decidir sobre o atingimento das metas de conhecimento. Ao deixarem de mensurar seu conhecimento e os pontos de mudança, as organizações deixam incompleto o ciclo de gestão do conhecimento; são ocorrências dissociadas de feedback que auxilie na realização de ajustes nos diversos elementos construtivos da gestão do conhecimento (PROBST et al., 2002, p. 37). 
Apresentado o referencial teórico, pode ser trabalhado o planejamento da pesquisa, definindo a estratégia de pesquisa e o protocolo de pesquisa para a condução dos estudos de caso.

\section{PLANEJAMENTO DA PESQUISA}

O estudo de caso foi adotado como estratégia de pesquisa, particularmente os estudos de caso múltiplos. O trabalho é de natureza exploratória, buscando desenvolver uma compreensão acerca do nível de adoção de práticas de gestão do conhecimento em um conjunto específico de empresas.

\section{É preciso criar indicadores-chave de desempenho para a gestão do conhecimento.}

A estratégia de pesquisa adotada é realizada através da aplicação de um protocolo de pesquisa. O protocolo é desenvolvido através da aplicação de um conjunto de técnicas, como entrevistas semiestruturadas, aplicação de questionários, análise documental e visita técnica às instalações das empresas estudadas (YIN, 1989).

A área de abrangência da pesquisa é a região Sudoeste do Estado do Paraná. Especificamente, foram estudadas organizações cooperativas nos municípios de São João, Coronel Vivida, Mariópolis e Capanema. Nestes municípios o total de organizações cooperativas é de vinte e duas. Foram realizados cinco estudos de caso e participaram da pesquisa vinte e dois funcionários das áreas gerencial, operacional e técnica. O Quadro 1 apresenta a descrição de funções dos entrevistados nas cinco cooperativas estudadas.

Dado o objetivo geral da pesquisa, que é o estudo do posicionamento de um conjunto de organizações cooperativas em relação à adoção de práticas de gestão do conhecimento, pode-se trabalhar um conjunto específico de questões para serem investigadas nos estudos de caso. Tais questões são apresentadas no Quadro 2.

As definições constitutivas e operacionais das variáveis presentes na declaração das questões norteadoras são elaboradas para fundamentar o desenvolvimento dos instrumentos de pesquisa (roteiros de entrevistas, questionários, check list da análise documental e relatórios de visita técnica). O Quadro 3 apresenta as descrições constitutivas e operacionais das variáveis envolvidas no estudo.

As questões norteadoras definem o roteiro de desenvolvimento do protocolo de pesquisa e organizam os elementos constituintes do relatório do estudo de caso. $\mathrm{Na}$ seqüência, são apresentados os resultados da aplicação do protocolo de pesquisa nas cinco organizações cooperativas selecionadas.

\section{A ADOÇÃO DA GESTÃO DO CONHECIMENTO NAS COOPERATIVAS}

A pesquisa realizada é, em essência, de natureza qualitativa; no entanto, construíram-se indicadores quantita-

\section{Quadro 1: Função desempenhada pelo entrevistado na cooperativa pesquisada.}

\begin{tabular}{ll}
\hline & \multicolumn{1}{c}{ Função desempenhada pelos entrevistados } \\
\hline R.1: Assistente Administrativo & R.12: Analista de Sistemas \\
R.2: Gerente Comercial & R.13: Gerente de Supermercado \\
R.3: Chefe de Produção & R.14: Médica Veterinária \\
R.4: Auxiliar de Produção & R.15: Assistente Administrativo \\
R.5: Setor de Crédito & R.16: Assistente de RH \\
R.6: Encarregado de Setor Operacional & R.17: Assistente Administrativo \\
R.7: Gerente & R.18: Engenheiro Agrônomo \\
R.8: Encarregado Operacional & R.19: Técnica de Produção \\
R.9: Suporte administrativo de canais de distribuição & R.20: Diretor Secretário \\
R.10: Gerente de negócios & R.21: Contabilista \\
R.11: Auxiliar Administrativo & R.22: Engenheiro \\
\hline
\end{tabular}

Fonte: Autores 
tivos para o estudo e comparação dos estudos de caso. Os dados são coletados, ordenados e processados na forma de quadros e gráficos, gerando uma descrição sobre a adoção de práticas de gestão do conhecimento. Os resultados são trabalhados em dois níveis: um geral, em que se desenvolve uma análise do grau de adoção das funções de gestão do conhecimento pelas cooperativas; o outro se refere aos casos propriamente ditos em que se estudam individual-

\section{Quadro 2: Questões norteadoras do estudo de caso.}

Q.1: A empresa desenvolve programas específicos (formais) voltados à gestão do conhecimento? Quais são?

Q.2: Quais os principais meios de acesso a 'novos conhecimentos'?

Q.3: Quais são os procedimentos internos adotados pelas cooperativas para a criação e captura do conhecimento?

Q.4: Quais são os procedimentos internos adotados pelas cooperativas para a codificação e organização do conhecimento?

Q.5: Quais são os procedimentos internos adotados pelas cooperativas para a disseminação do conhecimento?

Q.6: Quais são os procedimentos internos adotados pelas cooperativas para a avaliação e mensuração do conhecimento na empresa?

Q.7: 0 conhecimento é considerado um recurso estratégico? Há alinhamento entre as práticas de gestão do conhecimento adotadas e a estratégia empresarial desenvolvida pelas cooperativas? Explique.

Q.8: Há alinhamento entre os cursos formativos ou de qualificação fomentados pelas cooperativas e as práticas de gestão do conhecimento? Identifique as contribuições.

Fonte: Autores

Quadro 3: Definição constitutiva e operacional das variáveis do estudo.

Variável Definição constitutiva - DC / Definição operacional - DO

conhecimento DO - Processo que se integra a um modelo de gestão. 0 modelo de gestão pode ser descrito através de um conjunto de dimensões: estratégia, estrutura, processos e pessoas. Na dimensão processo é desenvolvida a gestão do conhecimento. A gestão do conhecimento apoia-se em funções e práticas de gestão do conhecimento.

DC - São as funções básicas de um sistema de gestão do conhecimento, realizadas através de processos e Funções de gestão práticas de gestão do conhecimento.

do conhecimento

DO - São citadas na literatura de gestão as seguintes funções: criar, capturar, organizar, codificar, disseminar, avaliar e mensurar

DC - Constituem um conjunto de categorias que organizam as ações de gestão do conhecimento desenvolvidas

Práticas de gestão pelas empresas. São responsáveis pela implementação das funções de gestão do conhecimento.

do conhecimento

DO - As categorias são: aprendizagem organizacional, educação corporativa, gestão do capital intelectual, gestão de competências e inteligência empresarial.

DC - Define uma medida para o posicionamento de uma organização quanto a adoção de práticas de gestão do conhecimento e da sua integração a estratégia empresarial desenvolvida.

Níveis de adoção

DO - Podem ser visualizados através do emprego de uma matriz de relacionamento. No eixo das ordenadas podem ser estabelecidas medidas para o nível de aplicação das funções de gestão do conhecimento; enquanto que no eixo das abscissas podem ser estabelecidas medidas para o nível de integração das funções de gestão do conhecimento à estratégia empresarial das cooperativas. Os quadrantes definem os níveis de adoção da gestão do conhecimento.

DC - São organizações de fins econômicos que não visam à obtenção de lucro.

Organizações DO - São formadas de associados que subscrevem quotas-parte desse empreendimento com direito de decisão cooperativas idêntico em que cada associado tem apenas um voto, sendo necessário o desenvolvimento de controle e monitoramento desses negócios pelos seus associados.

Fonte: Autores 
mente os níveis de aplicação e de integração à estratégia empresarial.

A síntese dos estudos de caso é realizada através de um gráfico que posiciona as organizações estudadas em relação à adoção de práticas de gestão do conhecimento, permitindo comparar o estágio evolutivo em que se encontram as organizações estudadas.

\section{Estratégia de gestão do conhecimento deve refletir a estratégia competitiva da empresa.}

O primeiro bloco de questões da pesquisa aborda o reconhecimento ou identificação do processo de criação do conhecimento e perguntou-se aos entrevistados se eles reconhecem a presença de algumas dimensões do processo de criação de um novo conhecimento na cooperativa. Para 95\%, a resposta foi afirmativa, ou seja, 95\% dos entrevistados reconhecem ou identificam nas suas cooperativas algum aspecto relativo ao processo de criação do conhecimento.

Para aqueles que responderam afirmativamente, foi perguntado quais seriam as dimensões reconhecidas. As respostas constam do Gráfico.

Para as dimensões identificadas no Gráfico 1, foram levantados quais são os procedimentos internos desenvolvidos nas cooperativas.
O Quadro 4 apresenta tais procedimentos, organizados pelo número de citações nas vinte e duas entrevistas realizadas (nos cinco estudos de caso).

Perguntado quais seriam os principais meios de criação do conhecimento para a cooperativa, obtiveram-se os dados da pesquisa, presentes no Gráfico 2 .

A pesquisa também busca compreender a percepção do entrevistado quanto ao grau de aplicação do processo de criação do conhecimento na cooperativa. O Gráfico 3 sintetiza tal percepção.

Outro aspecto estudado foi a percepção do entrevistado em relação à integração do processo de criação do conhecimento à estratégia empresarial da cooperativa, ao que os entrevistados assim responderam como apresentado no Gráfico 4.

O segundo bloco de questões trata do processo de captura do conhecimento. Perguntado quais, dentre os procedimentos internos que visam à captura do conhecimento, poderiam ser confirmados na organização cooperativa, foi apresentada uma lista de alternativas que foram assinaladas pelos entrevistados. Os resultados estão apresentados no Gráfico 5.

A percepção do grau de aplicação dos processos de captura do conhecimento nas cooperativas recebeu a avaliação por parte dos entrevistados mostrada no Gráfico 6.

$\mathrm{O}$ processo de captura do conhecimento se integra

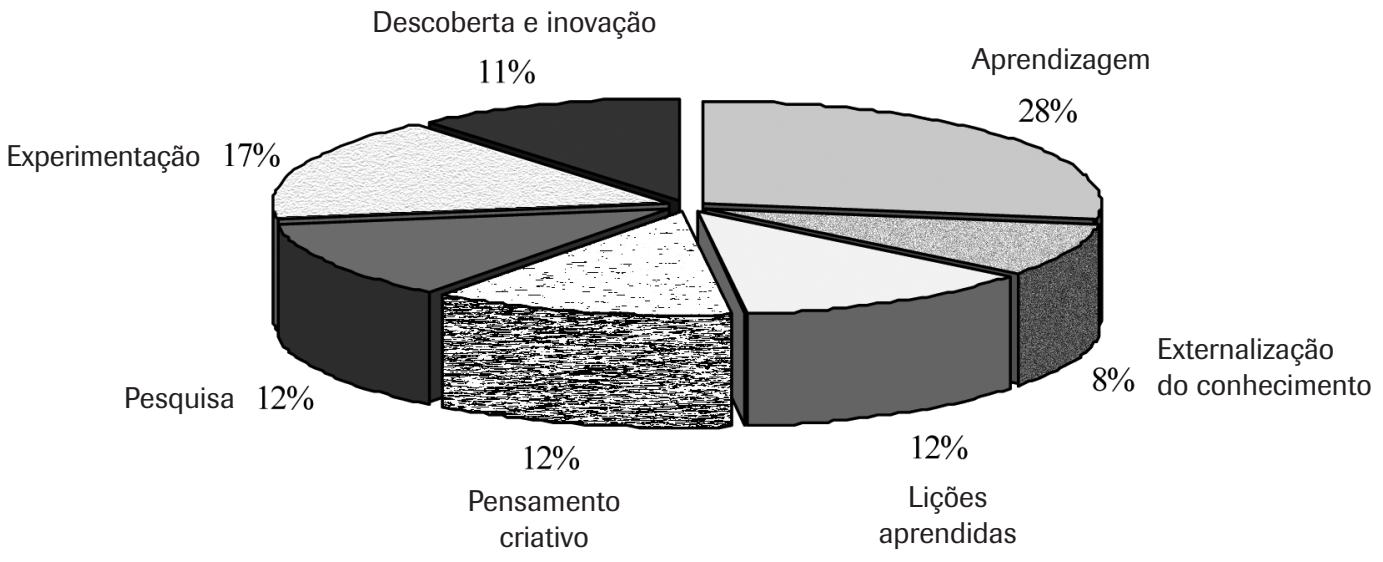

Gráfico 1: Dimensões do processo de criação do conhecimento presentes nas cooperativas. 
à estratégia empresarial nas medidas apresentadas no Gráfico 7.

O terceiro bloco de questões trabalha o processo de avaliação do conhecimento. A compreensão do processo de avaliação do conhecimento está relacionada com o valor estratégico do conhecimento para a organização. O Quadro 5 apresenta os itens que compõem a compreensão da organização em relação ao processo de avaliação.

Quadro 4: Procedimentos internos presentes nas cooperativas para a criação do conhecimento.

\begin{tabular}{|c|c|}
\hline Procedimentos & Incidência \\
\hline $\begin{array}{l}\text { A cooperativa valoriza as relações com clientes, fornecedores e concorrentes, através da identificação, } \\
\text { diferenciação, interação e adaptação de produtos e serviços aos clientes. }\end{array}$ & 13 \\
\hline Desenvolvimento pessoal e coletivo no campo humano. & 13 \\
\hline Aprendizagem com os profissionais das áreas. & 13 \\
\hline A autoaprendizagem, em que o indivíduo determina as etapas e o ritmo de aprendizagem. & 9 \\
\hline Obtenção de experiências nos trabalhos realizados. & 9 \\
\hline $\begin{array}{l}\text { A cooperativa viabiliza a aprendizagem por experimentação, que envolve a busca sistemática e o teste de novos } \\
\text { conhecimentos. }\end{array}$ & 8 \\
\hline Desenvolvimento de lideranças internas, externas. & 8 \\
\hline A cooperativa lança mão de especialistas externos para a aprendizagem. & 7 \\
\hline Descoberta e formação de novos líderes. & 7 \\
\hline $\begin{array}{l}\text { Na cooperativa é oportunizada a adoção do pensamento sistêmico e criativo, aceitando que todos são } \\
\text { responsáveis igualmente. }\end{array}$ & 4 \\
\hline
\end{tabular}

Fonte: Autores

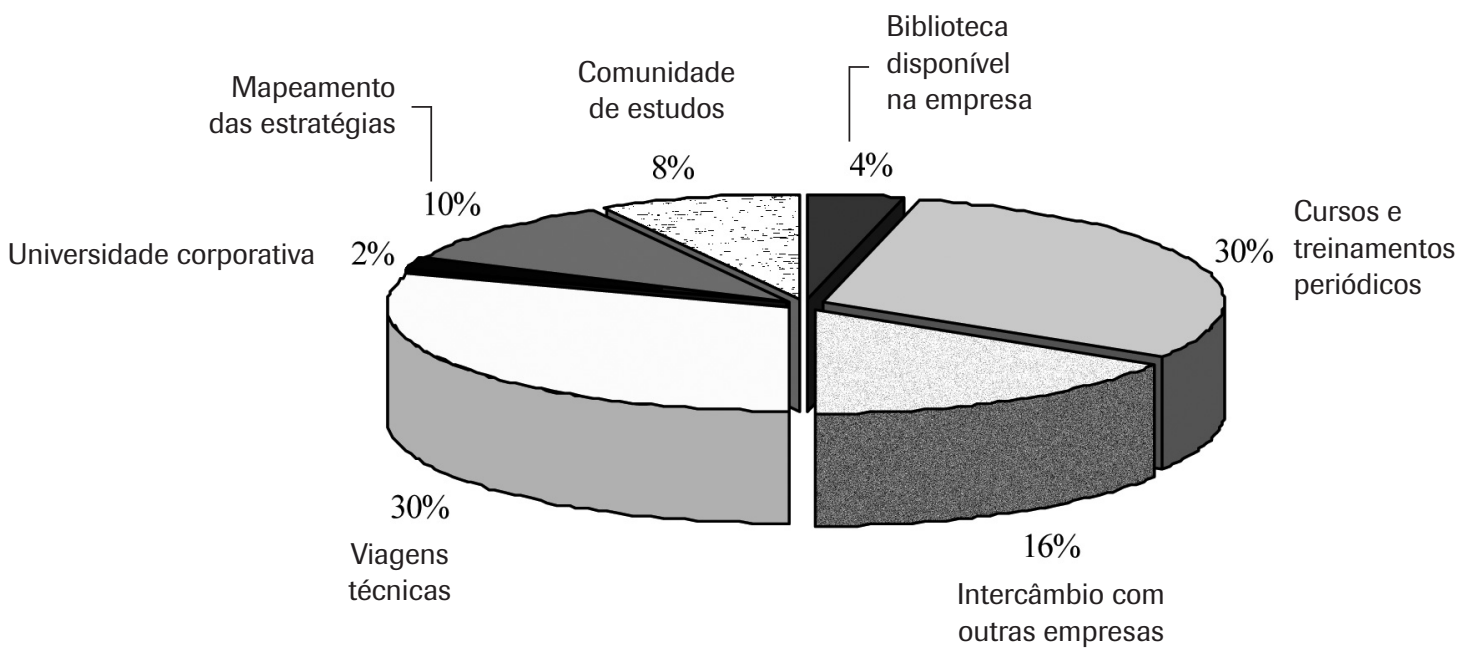

Gráfico 2: Meios de criação do conhecimento reconhecidos na cooperativa. 
$\mathrm{Na}$ avaliação dos entrevistados, o grau de aplicação do processo de avaliação do conhecimento nas cooperativas recebeu a avaliação mostrada no Gráfico 8.

A avaliação do conhecimento integrada à estratégia da cooperativa foi interpretada pelos entrevistados como apresentado no Gráfico 9.

Sobre o processo de organização e codificação do conhecimento (quarto bloco de questões), foi solicitado ao entrevistado reconhecer ou identificar determinados proce- dimentos adotados pelas cooperativas, conforme mostrado no Quadro 6.

O Gráfico 10 apresenta a percepção por parte dos entrevistados do grau de aplicação da organização e codificação do conhecimento nas cooperativas.

A integração do processo de organização e codificação do conhecimento à estratégia empresarial da cooperativa foi interpretada pelos entrevistados conforme apresentado no Gráfico 11.

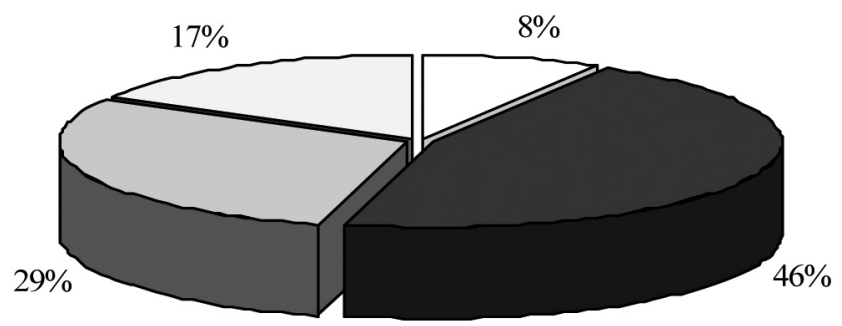

$\square$ Baixo $\square$ Médio $\square$ Bom $\square$ Excelente

Gráfico 3: Grau de aplicação da criação do conhecimento nas cooperativas.

Fonte: Autores

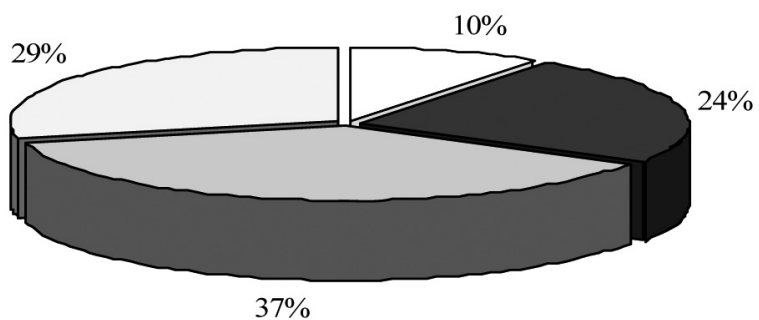

$\square$ Inexistente $\quad \square$ Baixo $\quad \square$ Médio $\quad \square$ Bom

Gráfico 4: Integração da criação do conhecimento à estratégia da cooperativa.

Fonte: Autores 
O processo de disseminação do conhecimento é trabalhado no quinto bloco de questões. O objetivo central é identificar quais procedimentos são praticados pelas cooperativas. O Quadro 7 apresenta um resumo dos procedimentos identificados.

O grau de aplicação do processo de disseminação do conhecimento nas cooperativas recebeu a avaliação mostrada no Gráfico 12.
Os entrevistados percebem a integração do processo de disseminação do conhecimento à estratégia empresarial conforme apresentado no Gráfico 13.

No sexto bloco de questões, a mensuração do conhecimento foi definida como sendo a capacidade de medir o desempenho da solução implementada e monitorar a adequação da solução adotada aos objetivos estratégicos

\section{Avaliação, discução e aplicação de idéias surgidas em todos os níveis da organização}

A efetiva aquisição

de conhecimento



Gráfico 5: Procedimentos para a captura do conhecimento adotados pelas cooperativas.

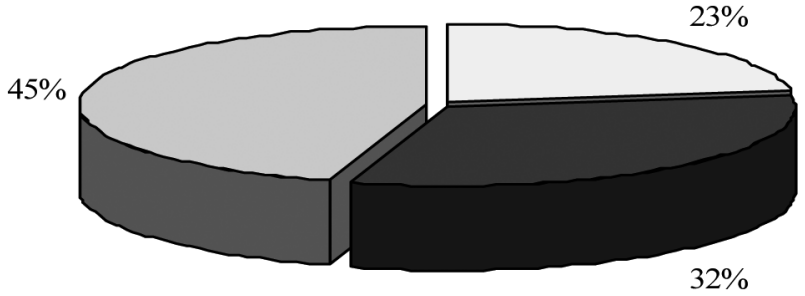

$\square$ Baixo $\square$ Médio $\square$ Bom

Gráfico 6: Grau de aplicação da captura do conhecimento nas cooperativas. 


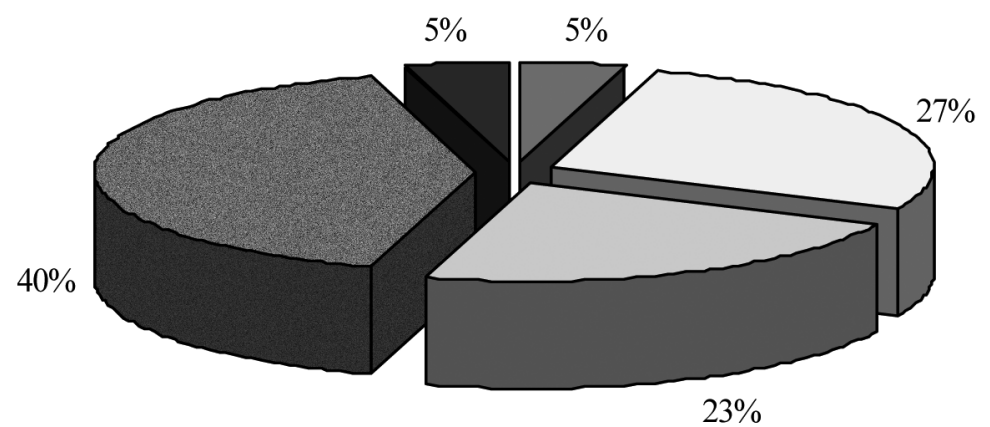

$\square$ Inexistente $\square$ Baixo $\square$ Médio $\square$ Bom $\square$ Excelente

Gráfico 7: Grau de integração da captura do conhecimento à estratégia da cooperativa.

Fonte: Autores

Quadro 5: Valor da avaliação do conhecimento.

\begin{tabular}{lc}
\hline Descrição dos ‘valores’ & Incidência \\
\hline Aplicabilidade dos conhecimentos individuais no campo prático da organização. & 14 \\
Avaliar a formação acadêmica individual. & 12 \\
Avaliar a sua qualidade e aplicabilidade. & 11 \\
Filtrar a informação. & 8 \\
Verificar e considerar a fonte do conhecimento. & 8 \\
Aplicação dos conhecimentos individuais na prática pessoal e coletiva. & 8 \\
Resultados obtidos com a aplicação efetiva de um determinado conhecimento. & 7 \\
\hline
\end{tabular}

Fonte: Autores

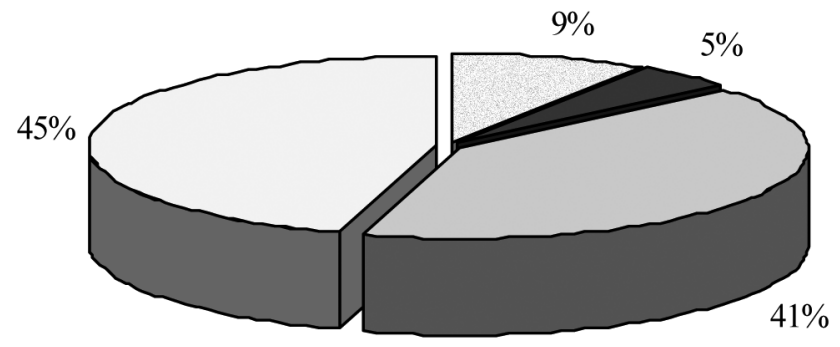

$\square$ Inexistente $\quad \square$ Baixo $\quad \square$ Médio $\quad \square$ Bom

Gráfico 8: Grau de aplicação da avaliação do conhecimento nas cooperativas.

Fonte: Autores 
de negócio. Considerando as práticas de mensuração do conhecimento, perguntou-se aos entrevistados quais os procedimentos adotados pelas cooperativas. As respostas estão sumarizadas no Quadro 8.

Na percepção dos entrevistados, o grau de aplicação dos processos de mensuração do conhecimento nas cooperativas é avaliado conforme apresentado no Gráfico 14.

A integração do processo de mensuração do conhecimento à estratégia empresarial da cooperativa é interpretada pelos entrevistados de acordo com o Gráfico 15.

Para concluir o levantamento de dados, identificouse junto aos entrevistados qual a relevância de algumas práticas de gestão do conhecimento para as organizações estudadas. O Gráfico 16 apresenta a distribuição de um conjunto de práticas de gestão do conhecimento adotadas pelas cooperativas.

Analisando-se os dados apresentados, é importante observar a confirmação, por $95 \%$ dos entrevistados, acerca do reconhecimento e identificação das dimensões do processo de criação de um novo conhecimento na cooperativa.

Dessas dimensões, são citadas com maior incidência a aprendizagem e a experimentação, ou seja, elementos que podem ser adquiridos individualmente pelas pessoas, primeiro no processo de aprendizagem e, depois, aprendendo com as próprias experiências.

Dos resultados observa-se que, por um lado, os proce-

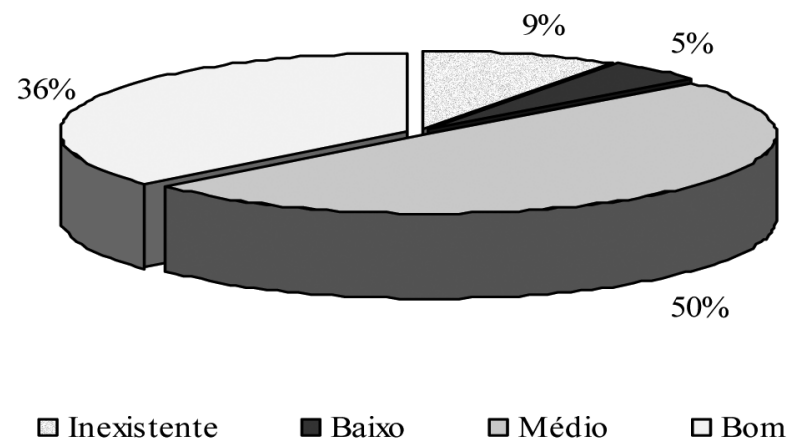

Gráfico 9: Integração da avaliação do conhecimento à estratégia da cooperativa.

Fonte: Autores

Quadro 6: Procedimentos de organização e codificação do conhecimento reconhecidos nas cooperativas.

\begin{tabular}{lc}
\hline \multicolumn{1}{c}{ Procedimentos } & Incidência \\
\hline Nos cursos e treinamentos periódicos que são realizados pela cooperativa. & 14 \\
Há disponibilidade de sistemas de armazenagem de competências e conhecimento, na forma de banco de & 11 \\
dados e banco de projetos. & 11 \\
Nas ações práticas do cotidiano da empresa. & 9 \\
São disponibilizados métodos para viabilizar o conhecimento formal aos envolvidos. & 9 \\
Quando há troca de experiências e questionamentos entre as pessoas do mesmo setor. & 8 \\
Quando há troca de experiência entre setores. & 8 \\
Quando as pessoas que retêm o conhecimento estão dispostas a compartilhar. & 7 \\
São realizadas triagens para reconhecer e classificar o conhecimento necessário à organização. & 7 \\
A organização viabiliza meios e ferramentas para compartilhamento do conhecimento. & \\
\hline
\end{tabular}

Fonte: Autores 
dimentos internos que visam a criação do conhecimento nas cooperativas incluem a valorização das relações entre clientes, fornecedores e concorrentes como um dos procedimentos mais frequentes. Para que ocorra essa valorização, as cooperativas identificam, diferenciam e adaptam os produtos e serviços aos clientes, no sentido de interagir proativamente promovendo a aprendizagem e o desenvolvimento pessoal e coletivo no campo humano, por meio de troca de conhecimento com os profissionais das diversas áreas da cooperativa. Por outro lado, destacam-se na criação do conhecimento os elementos externos à cooperativa, sob a forma de cursos e treinamentos. Esses dados são apontados no Gráfico 2 e destacam maior incidência nas alternativas cursos e treinamentos e viagens técnicas, ou seja, a busca de dados e informações que são transformados em conhecimento interno e de âmbito coletivo tem origem no ambiente externo da cooperativa.

Para que ocorra a captura do conhecimento, a cooperativa utiliza como procedimentos internos especialmente o incentivo à formação de seus colaboradores nas diversas áreas



$40 \%$

$\square$ Baixo $\square$ Médio $\square$ Bom $\square$ Excelente

Gráfico 10: Grau de organização e codificação do conhecimento nas cooperativas.

Fonte: Autores

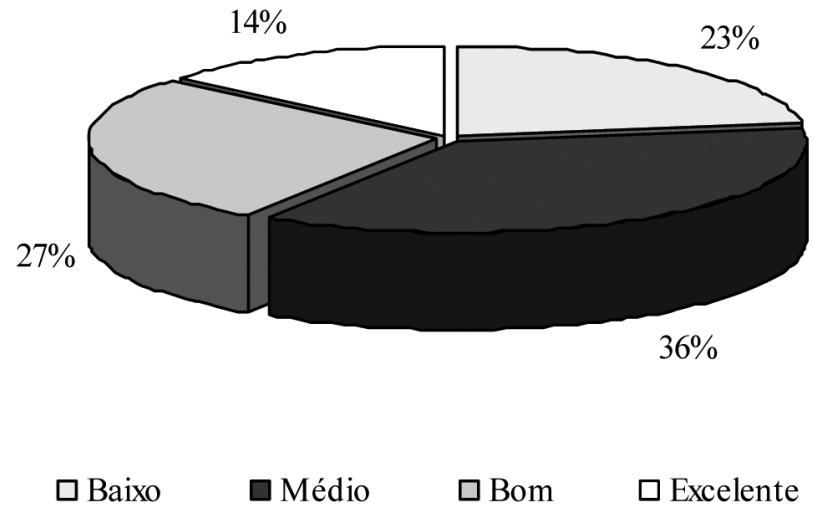

Gráfico 11: Integração da organização e codificação do conhecimento à estratégia da cooperativa. 
Quadro 7: Procedimentos adotados pela cooperativa para disseminar o conhecimento.

\begin{tabular}{lc}
\hline \multicolumn{1}{c}{ Procedimentos } & Incidência \\
\hline Palestras, cursos, simpósios, seminários, experimentos em campo. & 12 \\
Estão disponíveis recursos tecnológicos e de comunicação para disponibilizar o conhecimento. & 10 \\
Todas as informações e os conhecimentos podem ser acessados. & 9 \\
Os conhecimentos estão disponíveis, em tempo hábil e em local apropriado. & 8 \\
Dias de campo. & 8 \\
A Intranet. & 8 \\
Quando os conhecimentos estão disponíveis, não estão em tempo hábil e nem no local apropriado. & 7 \\
O repasse de experiência e o conhecimento de cada membro da equipe faz com que todos aprendam. & 7 \\
\hline
\end{tabular}

Fonte: Autores



$\square$ Inexistente $\square$ Baixo $\square$ Médio $\square$ Bom $\square$ Excelente

Gráfico 12: Grau de disseminação do conhecimento nas cooperativas.

Fonte: Autores

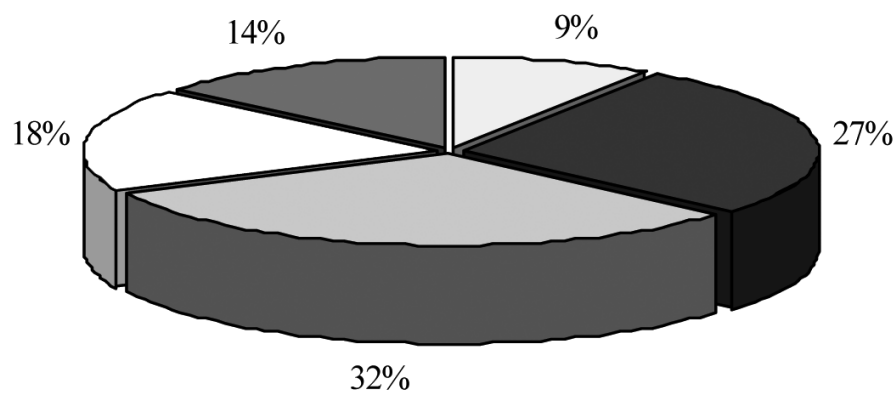

$\square$ Inexistente $\quad \square$ Baixo $\square$ Médio $\square$ Bom $\square$ Excelente

Gráfico 13: Integração da disseminação do conhecimento à estratégia das cooperativas. 
Gonçalves, L .C.; Pinheiro de Lima, E.; Gouvêa da Costa, S. E. Um estudo sobre a adoção de práticas de gestão do conhecimento em organizações cooperativas. Produção, v. 19, n. 1, p. 163-189, 2009

Quadro 8: Mensuração do conhecimento nas cooperativas.

\begin{tabular}{lc}
\hline \multicolumn{1}{c}{ Alternativas } & Incidência \\
\hline Verifica-se periodicamente o atingimento das metas, com isso medimos o ‘conhecimento’ da empresa. & 13 \\
Observa-se a manutenção da competitividade da empresa no âmbito dos serviços e de produtos. & 6 \\
Através da competência, do interesse e das atitudes de cada indivíduo que atua na empresa. & 6 \\
Atrelar o conhecimento à produtividade. & 5 \\
No grau de desenvolvimento de novos processos e procedimentos que garantem segurança e estabilidade & 5 \\
econômica e social para a organização. & 4 \\
São utilizados testes periódicos pelos setores e departamentos da organização cooperativa. & 4 \\
Através do grau de comprometimento dos indivíduos com novas descobertas. & 3 \\
Na avaliação no nível de criatividade individual e coletiva expressada dentro da organização. & \\
\hline Fonte: Autores
\end{tabular}

Fonte: Autores

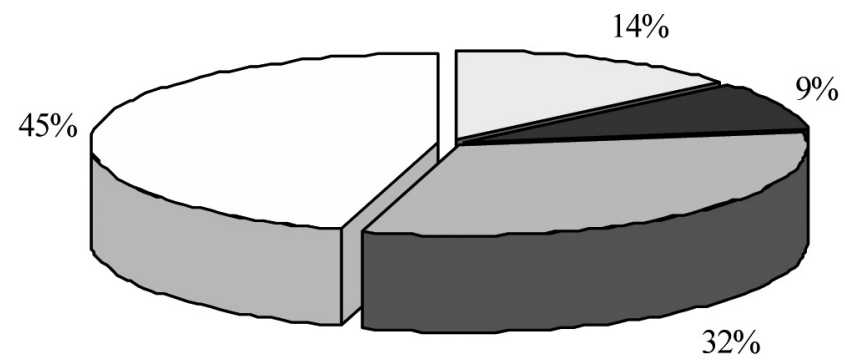

$\square$ Inexistente $\quad \square$ Baixo $\quad \square$ Médio $\quad \square$ Bom

Gráfico 14: Grau de aplicação da mensuração do conhecimento nas cooperativas. Fonte: Autores



$32 \%$

$\square$ Inexistente $\quad \square$ Baixo $\quad \square$ Médio $\quad \square$ Bom $\quad \square$ Excelente

Gráfico 15: Integração da mensuração do conhecimento à estratégia das cooperativas. Fonte: Autores 
do conhecimento, valorizando os profissionais que detêm e buscam o conhecimento e o autodesenvolvimento. Além disso, as cooperativas utilizam como procedimento interno à captura do conhecimento o incentivo à aquisição de habilidades e experiências que permitam manter as competências profissionais. O desenvolvimento e a manutenção de um conjunto de competências é o 'motor' que anima o processo de captura do conhecimento.

Após utilizar-se de procedimentos internos que visam à captura do conhecimento, os resultados da pesquisa revelam as preocupações das cooperativas quanto ao conhecimento adquirido através da avaliação da aplicabilidade dos conhecimentos individuais no campo prático da organização e da avaliação da formação acadêmica individual dos colaboradores.

Constata-se que as cooperativas da pesquisa detêm, de forma reconhecida, procedimentos de organização e codificação do conhecimento, que foram citados pelos entrevistados, destacando-se, mais uma vez, os cursos e treinamentos periódicos que são realizados por elas.

Algumas cooperativas da pesquisa utilizam procedimentos internos na disseminação do conhecimento. O procedimento mais citado consiste, após a realização de palestras, cursos, simpósios, seminários, experimentos em campo, das reuniões de departamentos, em que se utiliza da comunicação verbal para disseminar o conhecimento.

É possível reconhecer a compreensão de que o conhecimento residente nas cooperativas se dissemina quando da participação de alguns dos colaboradores nesses eventos, enquanto que, para os demais, são disponibilizados relatos do conhecimento capturado e assim, disseminado.

Com relação à função mensurar o conhecimento nas cooperativas, os resultados da pesquisa revelam que o processo de mensuração tem como elementos o atingimento das metas e a manutenção da competitividade da cooperativa, no âmbito dos seus serviços e de produtos.

O reconhecimento de que a gestão do conhecimento temse manifestado na ação prática nas cooperativas é confirmado pelos entrevistados, destacando-se a capacitação e o desenvolvimento de pessoas e a aprendizagem organizacional.

\section{POSICIONAMENTO DAS COOPERATIVAS EM RELAÇÃO À ADOÇÃO DA GESTÃO DO CONHECIMENTO}

A análise do posicionamento das cooperativas em relação

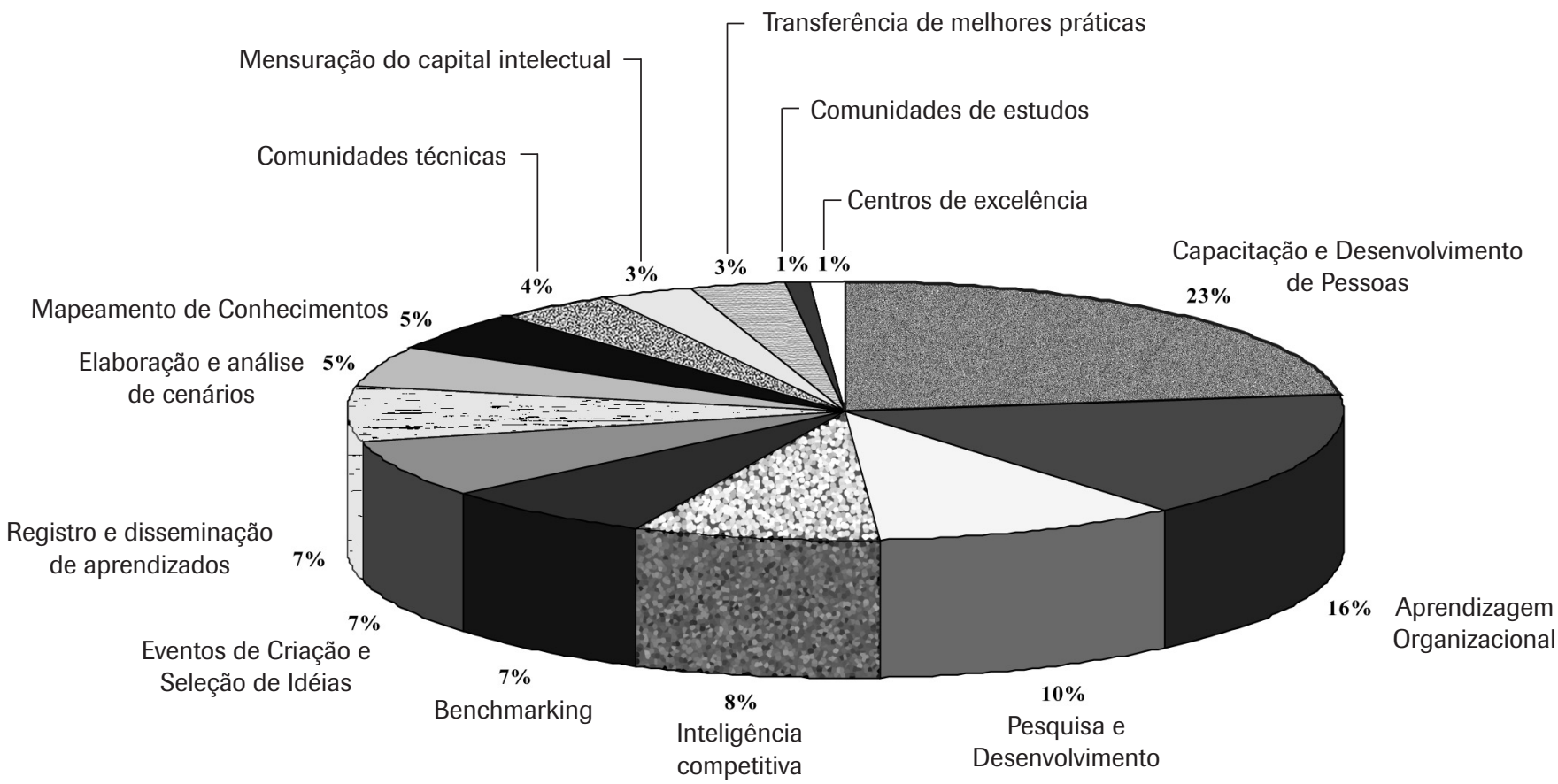

Gráfico 16: Práticas da gestão do conhecimento implementadas nas cooperativas.

Fonte: Autores 
ao grau de adoção de práticas de gestão do conhecimento é realizada:

- Avaliando-se individualmente as respostas dadas à percepção do grau de aplicação das funções de gestão do conhecimento (criação, captura, avaliação, organização e codificação, disseminação e mensuração) em relação a uma escala de cinco pontos: inexistente (0), baixo (1), médio (2), bom (3) e excelente (4);

- Avaliando-se individualmente as respostas dadas à percepção do grau de integração das funções de gestão do conhecimento à estratégia empresarial das cooperativas estudadas, em relação a uma escala de cinco pontos: inexistente (0), baixo (1), médio (2), bom (3) e excelente (4);

- O posicionamento das cooperativas é gerado pelo cruzamento do grau de aplicação versus grau de integração à estratégia empresarial das cooperativas estudadas.

Os gráficos desta seção apresentam a frequência das notas três e quatro de cada uma das funções da gestão do conhecimento, organizados por cooperativa.

Na Coop_1, por exemplo, a função criação do conhecimento apresenta $50 \%$ das notas três e quatro, ou seja, metade dos respondentes assinalou notas três ou quatro na sua avaliação, conforme pode ser observado no Gráfico 17 .

Para o grau de integração das funções de gestão do conhecimento à estratégia empresarial das cooperativas, a Coop_1 obteve a seguinte avaliação apresentada no Gráfico 18.

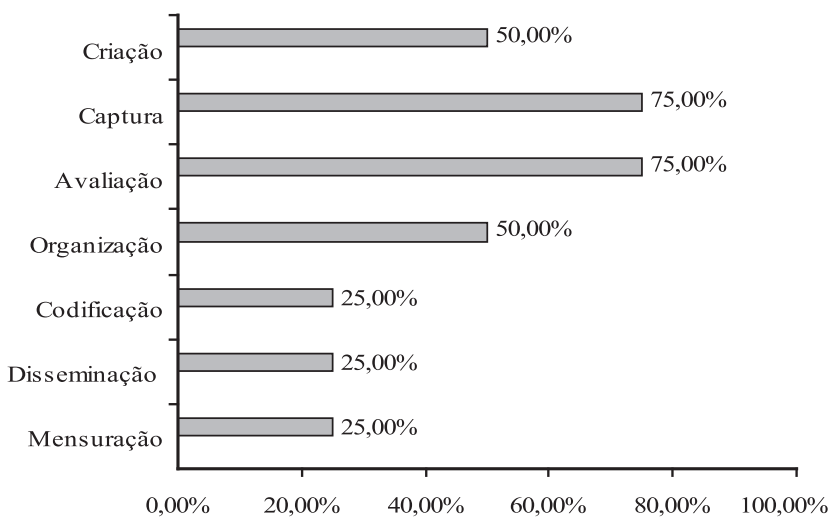

Gráfico 17: Frequência do grau de aplicação das funções de gestão do conhecimento na Coop_1.

Fonte: Autores
Na Coop_2 os percentuais representativos do grau de aplicação das funções da gestão do conhecimento são mostrados no Gráfico 19.

Com relação à frequência do grau de integração das funções da gestão do conhecimento à estratégia empresarial da Coop_2, a pesquisa não obteve respostas com notas três e quatro.

Quanto a Coop_3, os percentuais relativos ao grau de aplicação das funções de gestão do conhecimento e da sua integração à sua estratégia empresarial estão representados



\section{Gráfico 18: Frequência do grau de integração das funções de gestão do conhecimento à estratégia da Coop_1.}

Fonte: Autores

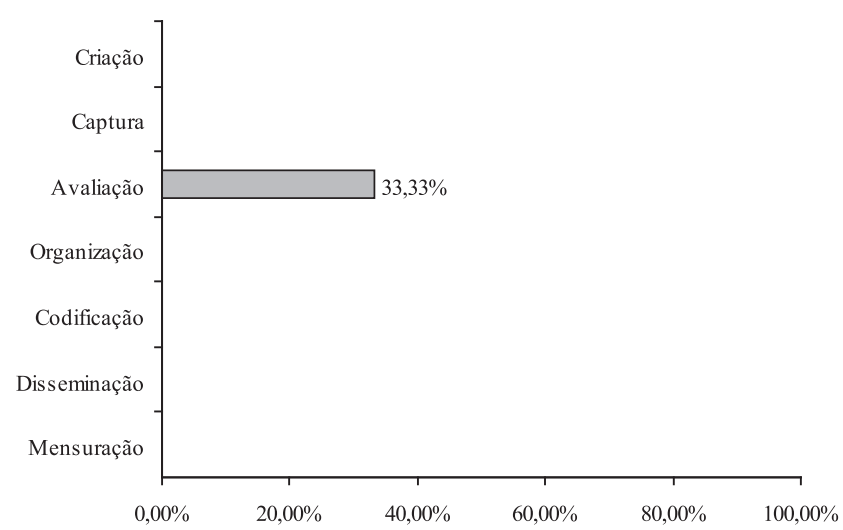

Gráfico 19: Frequência do grau de aplicação das funções de gestão do conhecimento na Coop_2.

Fonte: Autores 
no Gráfico 20 e no Gráfico 21, respectivamente.

Os percentuais representativos do grau de aplicação das funções de gestão do conhecimento e da sua à estratégia empresarial da Coop_4 estão representados no Gráfico 22 e no Gráfico 23, respectivamente.

Por fim, apresentam-se os percentuais representativos do grau de aplicação das funções de gestão do conhecimento e da sua integração à estratégia empresarial da Coop_5, conforme pode ser observado no Gráfico 24 e no Gráfico 25 , respectivamente.

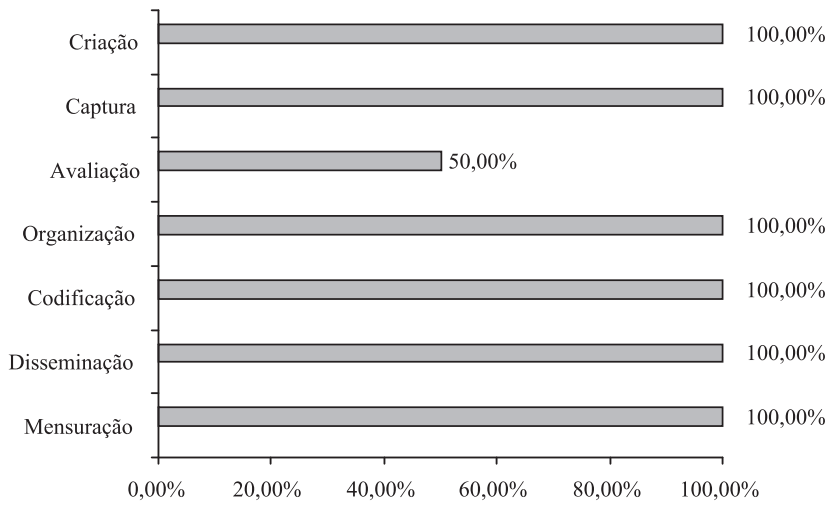

Gráfico 20: Frequência do grau de aplicação das funções de gestão do conhecimento na Coop_3.

Fonte: Autores



Gráfico 21: Frequência do grau de integração das funções da gestão do conhecimento à estratégia da Coop_3.

Fonte: Autores
O Gráfico 26 apresenta uma compilação geral dos resultados de todas as cooperativas para o grau de aplicação das funções de gestão do conhecimento, enquanto que o Gráfico 27 desenvolve uma análise geral para o grau de integração das funções de gestão do conhecimento à estratégia das cooperativas.

Os grupos de respondentes foram, também, analisados em separado, ou seja, o Gráfico 28 apresenta os percentuais estabelecidos para o grau de aplicação das funções da gestão do conhecimento, no nível gerencial, enquanto que o Gráfico



Gráfico 22: Frequência do grau de aplicação das funções de gestão do conhecimento na Coop_4.

Fonte: Autores

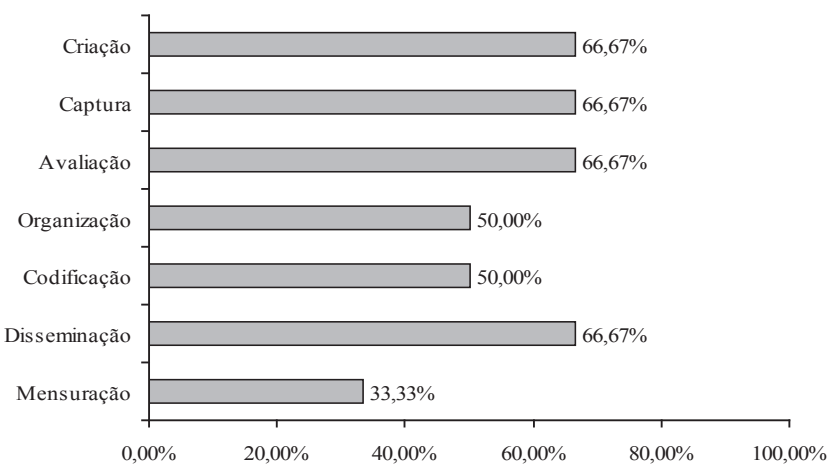

Gráfico 23 - Frequência do grau da integração das funções de gestão do conhecimento à estratégia da Coop_4.

Fonte: Autores 
30 as desenvolve no nível operacional. Da mesma maneira desenvolvem-se as análises quanto ao grau de integração à estratégia das cooperativas, sendo que o Gráfico 29 as desenvolve para o nível gerencial e o Gráfico 31 para o nível operacional.

Sobre a frequência geral do nível operacional, tem-se os gráficos a seguir:

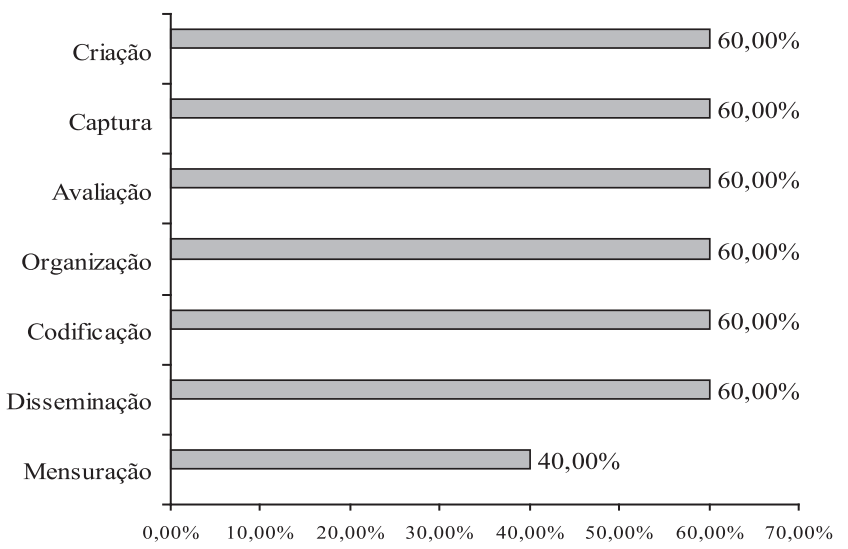

Gráfico 24: Frequência do grau de aplicação das funções de gestão do conhecimento na Coop_5.

Fonte: Autores

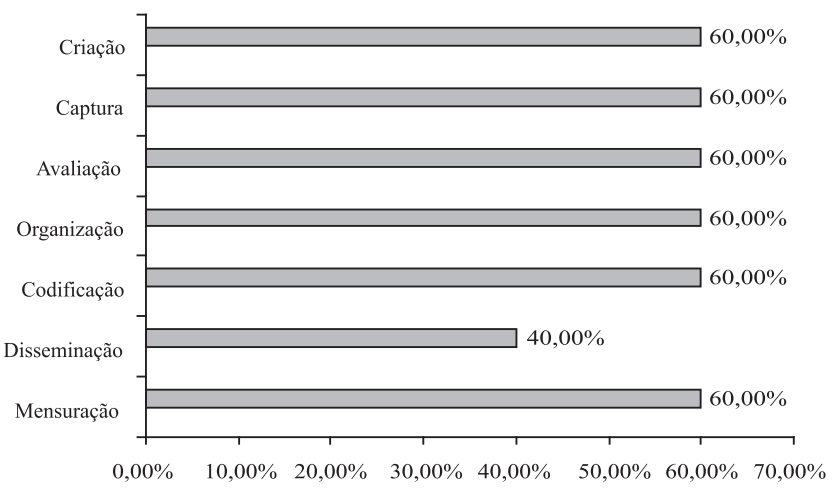

Gráfico 25: Frequência do grau de integração das funções de gestão do conhecimento à estratégia da Coop_5.

Fonte: Autores
Finalmente, a Figura 3 apresenta os critérios e procedimentos adotados para o posicionamento das organizações em relação à adoção da gestão do conhecimento.

A distribuição de frequência das duas variáveis ('aplicação das funções de gestão do conhecimento' e o 'nível de integração à estratégia da empresa'), constituem um par coordenado $(\mathrm{x}, \mathrm{y})$. O par ordenado é desenhado num plano cartesiano



Gráfico 26: Frequência geral do grau de aplicação das funções de gestão do conhecimento.

Fonte: Autores

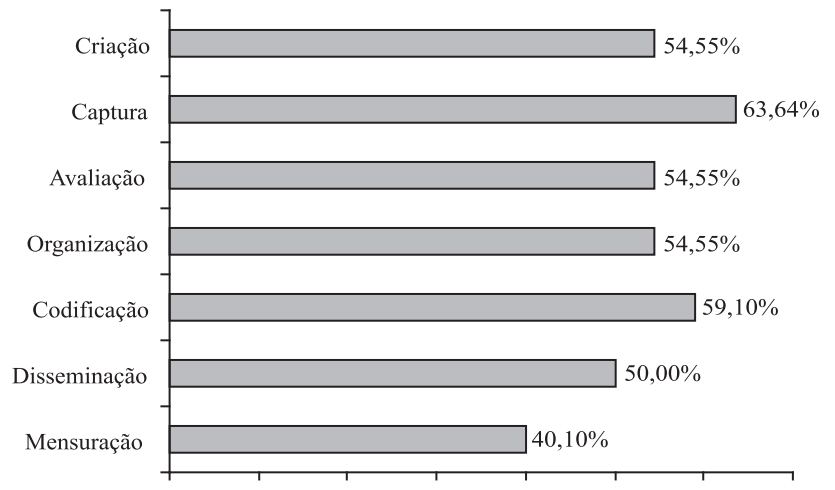

$0,00 \% \quad 10,00 \% \quad 20,00 \% \quad 30,00 \% \quad 40,00 \% \quad 50,00 \% \quad 60,00 \% \quad 70,00 \%$

Gráfico 27: Frequência geral do grau de integração das funções de gestão do conhecimento à estratégia das cooperativas.

Fonte: Autores 


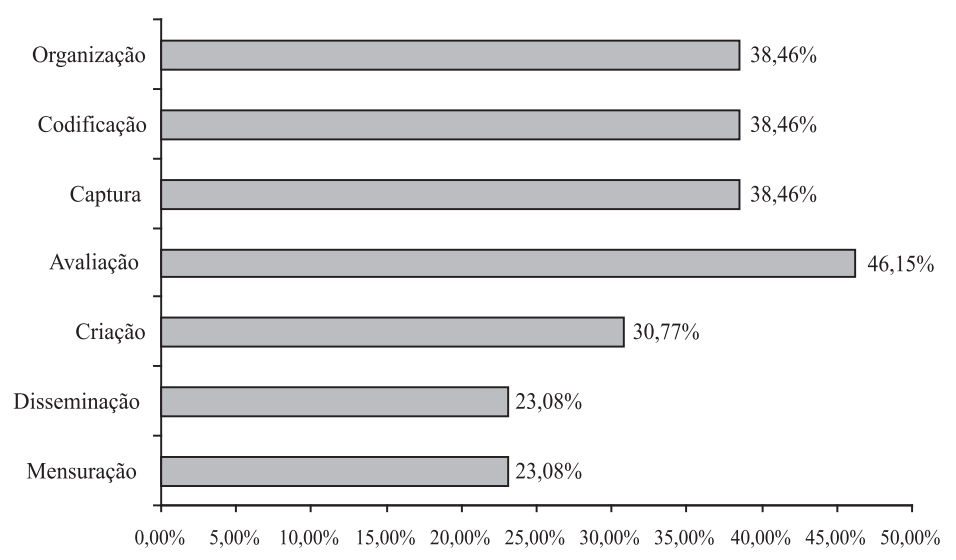

Gráfico 28: Frequência geral do grau de aplicação das funções da gestão do conhecimento estabelecida no nível gerencial das organizações cooperativas.

Fonte: Autores



Gráfico 29: Frequência geral do grau de integração das funções da gestão do conhecimento à estratégia das organizações cooperativas, estabelecida no nível gerencial.

Fonte: Autores

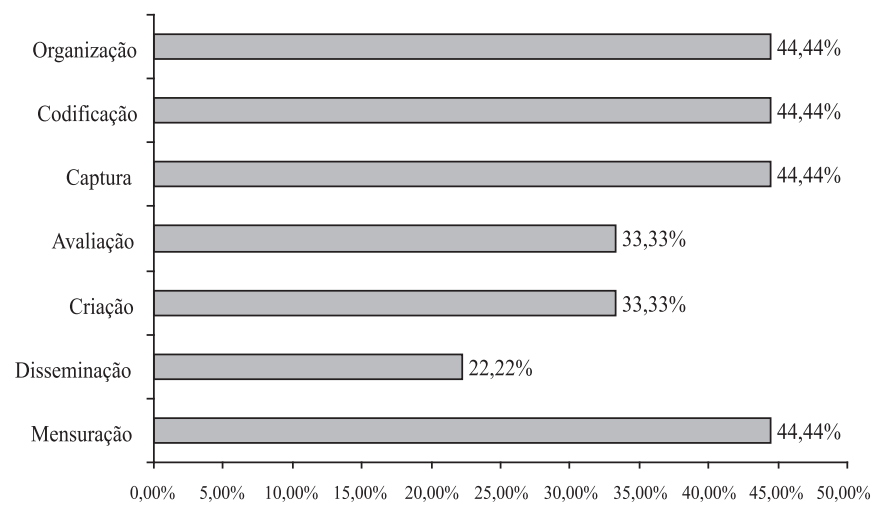

Gráfico 30: Frequência geral do grau de aplicação das funções da gestão do conhecimento estabelecida no nível operacional das organizações cooperativas.

Fonte: Autores 
Gonçalves, L .C.; Pinheiro de Lima, E.; Gouvêa da Costa, S. E. Um estudo sobre a adoção de práticas de gestão do conhecimento em organizações cooperativas. Produção, v. 19, n. 1, p. 163-189, 2009

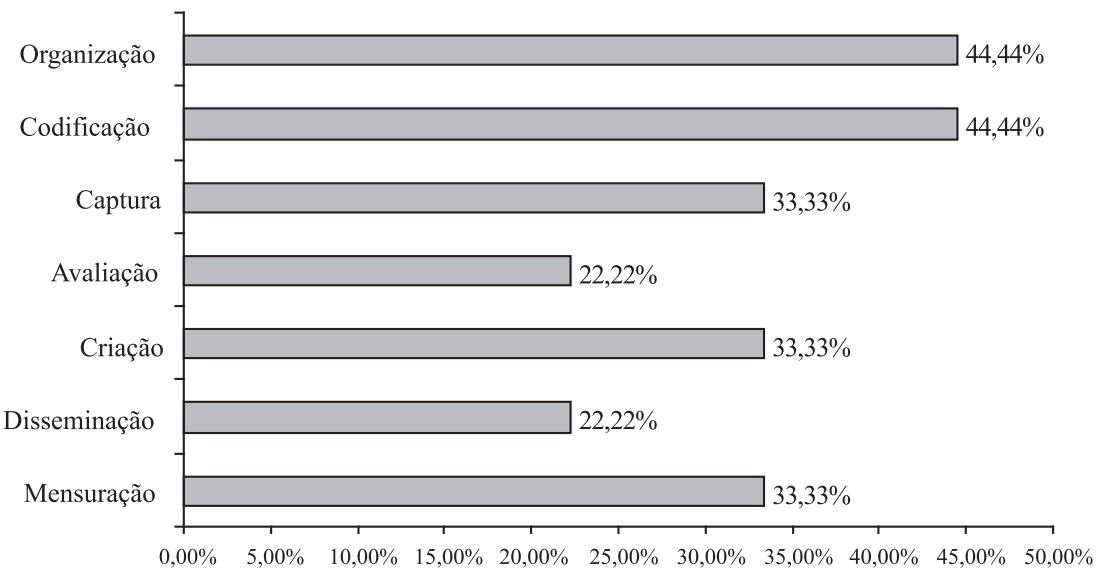

Gráfico 31: Frequência geral do grau de integração das funções da gestão do conhecimento à estratégia das organizações cooperativas, estabelecida no nível operacional.

Fonte: Autores

\section{Modelo de avaliação}

Funções de GC

Possíveis respostas

\begin{tabular}{|c|c|c|c|}
\hline Criação & 01 & \multicolumn{2}{|c|}{ Não se aplica à empresa (N/A) } \\
\hline Captura & 02 & & \\
\hline Avaliação & 03 & \multirow{2}{*}{\multicolumn{2}{|c|}{ Aplicável à empresa }} \\
\hline Organização & 04 & & \\
\hline Codificação & 05 & \multirow{7}{*}{$\begin{array}{c}\text { Grau de aplicação } \\
\text { Inexistente } \\
\text { Baixo } \\
\text { Parcial } \\
\text { Bom } \\
\text { Excelente }\end{array}$} & Nota atribuída \\
\hline Disseminação & 06 & & \\
\hline Mensuração & 07 & & 0 \\
\hline & & & 1 \\
\hline & & & 2 \\
\hline & & & 3 \\
\hline & & & 4 \\
\hline
\end{tabular}

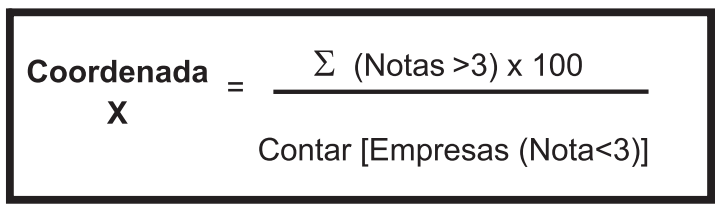

$$
\underset{\mathbf{Y}}{\underset{\mathbf{C}}{\text { Coordenada }}}=\frac{\sum(\text { Notas }>3) \times 100}{\text { Contar }[\text { Empresas }(\text { Nota }<3)]}
$$

Figura 3: Modelo de avaliação do grau de adoção. 
com quatro quadrantes, que tem no eixo das ordenadas a 'aplicação das funções de gestão do conhecimento', e no eixo das abscissas o 'nível de integração à estratégia da empresa'. Na Figura 4 são apresentados os níveis agregados em percentuais de frequência da aplicação das funções da gestão do conhecimento.

A Figura 5 apresenta o estudo do grau de integração das funções de gestão do conhecimento às estratégias empresarias das organizações cooperativas.

A partir dos resultados apresentados pode-se, em termos gerais, posicionar as organizações cooperativas em relação à adoção das funções de gestão do conhecimento, conforme apresentado na Figura 6. As funções pesquisadas posicionaram-se predominantemente em três quadrantes da 'Matriz de Adoção' das funções de Gestão do Conhecimento, matriz esta que apresenta o primeiro quadrante como o nível mais desenvolvido na adoção e aplicação das funções, bem como alto grau de percepção da integração desta função à estratégia empresarial da cooperativa. No 1o quadrante estão as funções captura (2), criação (1), avaliação (3), organização (4) e codificação (5). A função de gestão do conhecimento disseminação (6) situa-se bem no centro da matriz, com frequência de 50,00\%. Apenas a mensuração do conhecimento (7) encontra-se no $3^{\circ}$ quadrante da Matriz de Adoção.

Apresentados os gráficos e figuras com os resultados obtidos na pesquisa, observa-se que, quanto ao grau de adoção obtido pela distribuição de frequência, a função Captura do Conhecimento posiciona-se no $1^{\circ}$ quadrante da Matriz de Adoção das Funções de Gestão do Conhecimento. Observase, também, que esta função destaca-se em todas as cooperativas da pesquisa, geralmente com a influência de agentes externos à organização.

A função disseminação posicionou-se no centro da matriz, o que evidencia certa neutralidade no que se refere a adoção. Há necessidade, no entanto, de um estudo mais aprofundado das práticas de disseminação adotadas.

A função mensuração situa-se no $3-$ quadrante, significando que as organizações estudadas não adotam práticas de medição e avaliação dos processos de gestão do conhecimento.

O modelo de gestão do conhecimento encontra-se parcialmente implantado e com níveis diferenciados entre as funções. Há necessidade de se balancear a adoção das funções e, particularmente, incrementar os níveis de adoção de práticas de mensuração. Tais ações contribuirão para

\section{Grau de aplicação das funções de gestão do conhecimento}

\section{Empresas praticantes}

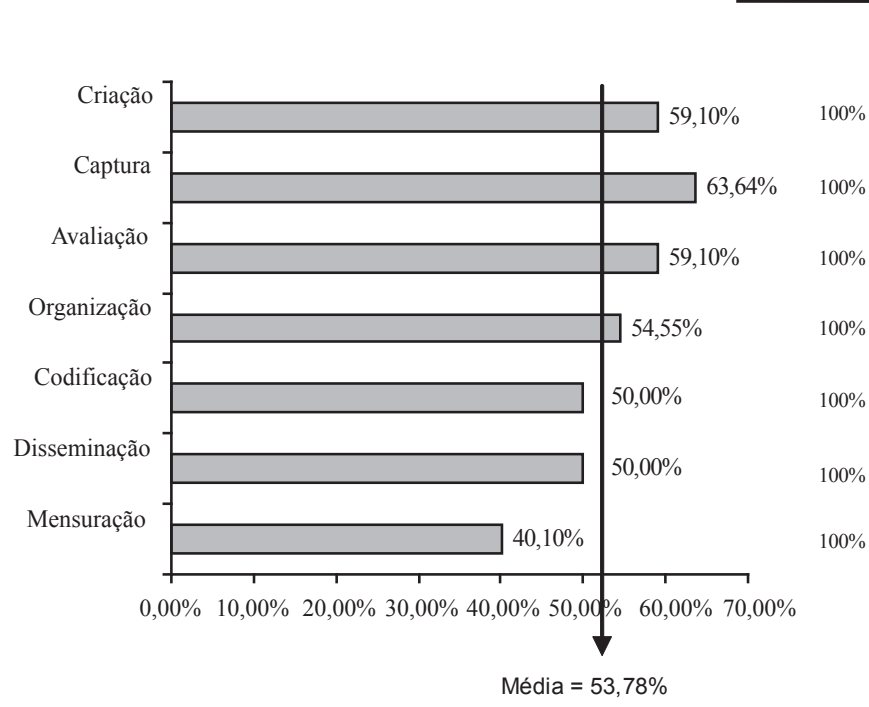

\section{Comentários}

- Funções relacionadas a treinamento e capacitação encontram-se maduras.

- As funções com menor grau de aderência/ maturidade são as que apresentam maiores oportunidades de melhoria nas organizações.

Figura 4: Níveis agregados da aplicação das funções de gestão do conhecimento.

Fonte: Autores 
Gonçalves, L .C.; Pinheiro de Lima, E.; Gouvêa da Costa, S. E. Um estudo sobre a adoção de práticas de gestão do conhecimento em organizações cooperativas. Produção, v. 19, n. 1, p. 163-189, 2009

Grau de integração das funções de gestão do conhecimento às estratégias das corporativas

\section{Empresas praticantes}

$100 \%$



Média $=53,78 \%$

\section{Comentários}

- Funções como a organização e codificação sugerem que o conhecimento é utilizado na estratégia.

- As funções com menor grau de incidência na integração às estratégias podem sofrer amadurecimento nas cooperativas.

Figura 5: Níveis agregados em percentuais de frequência da integração das funções de gestão do conhecimento às estratégias das cooperativas.

Fonte: Autores

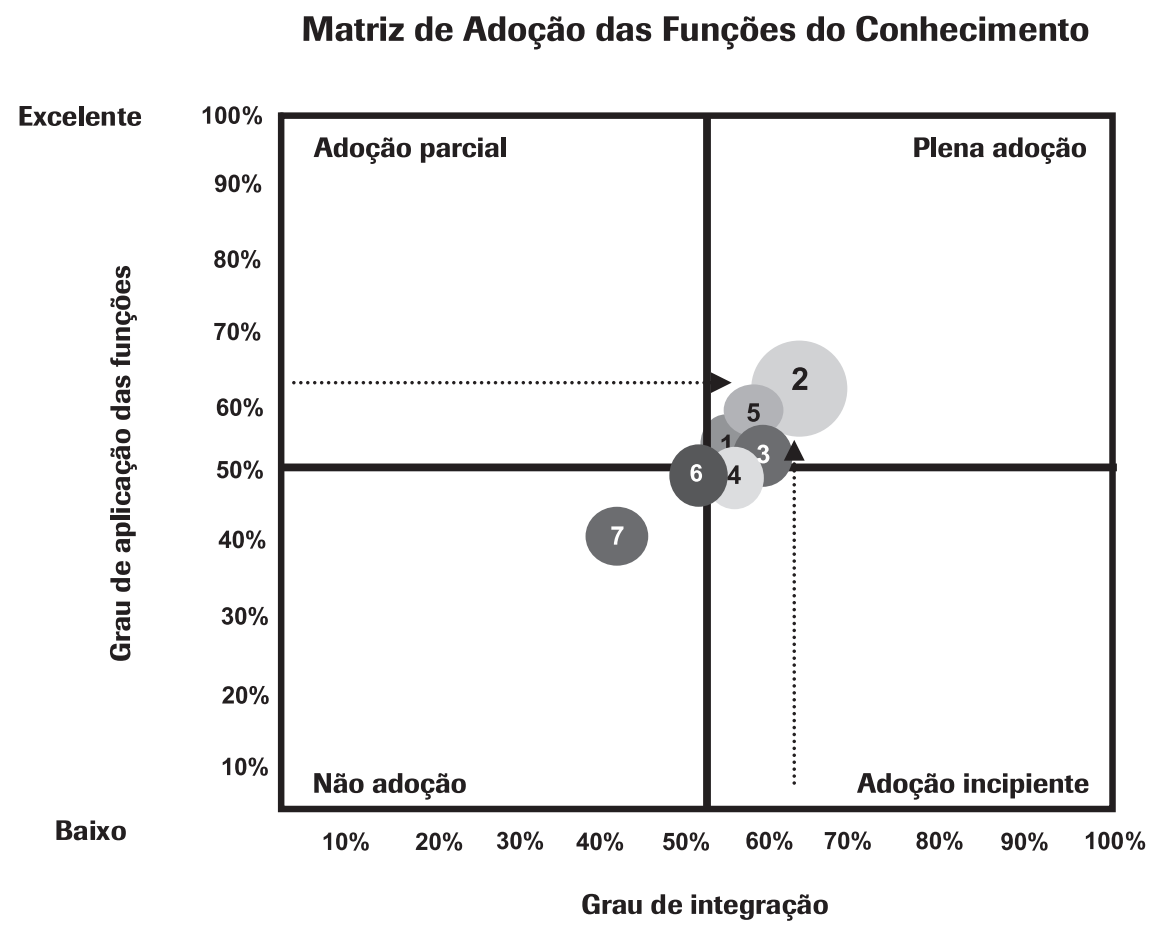

Figura 6: Grau de adoção das funções da gestão do conhecimento em cooperativas. 
a integração entre as funções de gestão do conhecimento, permitindo que se criem as condições necessárias para a gestão estratégica do conhecimento nas cooperativas estudadas.

\section{CONCLUSÃO}

Verificar o desenvolvimento das funções e a adoção de práticas de gestão do conhecimento permite avaliar o quanto as empresas estão avançando na implantação de modelos de gestão baseados em conhecimento. Foi este o aspecto central na análise dos dados obtidos na pesquisa.

Os resultados obtidos confirmam a presença de funções da gestão do conhecimento (formal e informal) nas organizações cooperativas pesquisadas, destacando-se a função captura do conhecimento como formalmente presente e em destaque, seguida pelas demais funções, que aparecem no mesmo quadrante da Matriz de Adoção das Funções de Gestão do Conhecimento, com pequenas diferenças na distribuição de frequência das mesmas, excetuando a mensuração. Tais funções apresentam certa neutralidade no que se refere à sua 'institucionalização', merecendo uma investigação mais profunda em relação ao seu nível de desenvolvimento nas organizações estudadas.

A pesquisa revelou que as funções desenvolvidas nas organizações cooperativas, tratadas como práticas organizacionais, apresentam uma lacuna quanto à função da gestão do conhecimento 'mensuração', que se localiza no $3^{3}$ quadrante da referida matriz. Destaca-se a necessidade de se implantar práticas específicas para avaliar o desempenho da função Gestão do Conhecimento, mediante a constru- ção de indicadores para os seus processos e práticas.

Para um aprofundamento do estudo realizado, é importante tratar questões relativas à maturidade no desenvolvimento do modelo de gestão do conhecimento, em que os diferentes níveis possam acomodar um número cumulativo de funções de gestão do conhecimento implementadas. Por outro lado, pode-se admitir uma escala de níveis de competência no desenvolvimento das respectivas funções de gestão do conhecimento do modelo proposto.

Este trabalho apresenta o desenvolvimento de um procedimento para conhecer o posicionamento das organizações cooperativas em relação ao desenvolvimento de funções da gestão do conhecimento. Observa-se, no entanto, a necessidade de um aprofundamento nos testes, no ajuste de escalas

\title{
$\Lambda$ identificação das práticas de gestão do conhecimento representam uma etapa no processo de desenvolvimento de um modelo específico de gestão
}

e na melhor definição das categorias e tipos trabalhados. Tal necessidade justifica-se pelo fato de que houve uma concentração no posicionamento de alguns elementos na 'Matriz de Adoção', sugerindo que se realize um estudo mais aprofundado no que se refere ao conteúdo, bem como em relação às escalas empregadas.

A identificação das práticas de gestão do conhecimento adotadas e do seu inter-relacionamento representam uma etapa no processo de desenvolvimento de um modelo específico de gestão para as organizações cooperativas. Propõe-se, também, enriquecer o desenvolvimento do modelo acrescentando aspectos que envolvam o estudo da sua dinâmica, particularmente no que se refere aos mecanismos de conversão do conhecimento.

\author{
Artigo recebido em 03/09/2007 \\ Aprovado para publicação em 10/10/2008
}




\section{REFERÊNCIAS}

ALMEIDA, D. A.; LEAL, F.; PINHO, A. F.; FAGUNDES, L. D. Gestão do conhecimento na análise de falhas: mapeamento de falhas através de sistema de informação. Produção, São Paulo, v. 16, n. 1, p. 171-188, 2006.

AUGIER, M.; KNUDSEN, T. The architecture and design of the knowledge organization. Journal of Knowledge Management, v. 8, n. 4, p. $6-20,2004$.

BARNEY, J. Firm resources and sustained competitive advantage. Journal of Management, v. 17, n. 1, p. 99-120, 1991.

BECKMAN, T. The current state of knowledge management. In: LIEBOWITZ, J. (Ed.) Knowledge Management Handbook. New York: CRC Press, 1999.

BROWN, J. S.; DUGUID, P. Knowledge and organization: a social-practice perspective. Organization Science, v. 12, n. 2, p. 198-213, 2001.

CANONGIA, C.; SANTOS, D. M.; SANTOS, M. M.; ZACKIEWICZ, M. Foresight, inteligência competitiva e gestão do conhecimento: instrumentos para a gestão da inovação. Gestão \& Produção, v. 11, n. 2, p. 231-238, 2004.

CHAE B.; BLOODGOOD, J. M. The paradoxes of knowledge management: an eastern philosophical perspective. Information and Organization, v. 16, n. 1, p. 1-26, 2006.

CHOI, B.; POON, S. K.; DAVIS, J. G. Effects of knowledge management strategy on organizational performance: a complementarity theory-based approach. Omega, v. 36, n. 2, p. 235-251, 2008.

DAVENPORT, T. H.; PRUSAK, L. Conhecimento empresarial: como as organizações gerenciam o seu capital intelectual. Rio de Janeiro: Campus, 1998.

DAWSON, R. Knowledge capabilities as the focus of organizational development and strategy. Journal of Knowledge Management, v. 4, n. 4, p. 320-327, 2000.
DEL REY CHAMORRO, F. M.; ROY, R.; VAN WEGEN, B.; STEELE, A. A framework to create key performance indicators for knowledge management solutions. Journal of Knowledge Management, v. 7, n. 2, p. 46-62, 2003.

EKSTEDT, E. Human capital in an age of transition: knowledge development and corporate renewal. Stockholm: Allmanna Forlaget, 1988.

GUPTA, B.; IYER, L. S.; ARONSON, J. E. Knowledge Management: practices and challenges. Industrial Management \& Data Systems, v. 100, n. 1, p. 17-21, 2000.

HALAWI, L. A.; MCCARTHY, R. V.; ARONSON, J. E. Knowledge management and the competitive strategy of the firm The Learning Organization, v. 13, n. 4, p. 384-397, 2006.

HSM MANAGEMENT. A gestão do conhecimento na prática. v. 8, n. 42, 2004.

JUNG, J.; CHOI, I.; SONG, M. An integration architecture for knowledge management systems and business process management systems. Computers in Industry, v. 58, n. 1, p. 21-34, 2007.

KAKABADSE, N. K.; KAKABADSE, A.; KOUZMIN, A. Reviewing the knowledge management literature: towards a taxonomy. Journal of Knowledge Management, v. 7, n. 4, p. 75-91, 2003.

KIM, Y. G.; YU, S. H.; LEE, J. H. Knowledge strategy planning: methodology and case. Expert Systems with Applications, v. 24, n. 3, p. 295-307, 2003.

KJÆRGAARD, A.; KAUTZ, K. A process model of establishing knowledge management: insights from a longitudinal field study. Omega, v. 36 , n. 2, p. 282-297, 2008.

LEE, S. M.; HONG, S. An enterprise-wide knowledge management system infrastructure. Industrial Management \& Data Systems, v. 102, n. 1, p. 17-25, 2002.

MARQUÉS, D. P.; SIMÓN, F. J. G. The effect of knowledge management practices on firm performance. Journal of Knowledge Management, v. 10, n. 3, p. 143-156, 2006.
MEYER, B.; SUGIYAMA, K. The concept of knowledge in KM: a dimensional model. Journal of Knowledge Management, v. 11, n. 1, p. 17-35, 2007.

MORGAN, G. Imagens da organização. São Paulo: Atlas, 1995.

NADLER, D.; GERSTEIN, M. S.; SHAW, R. B. Arquitetura organizacional: a chave para a mudança empresarial. 2. ed. Rio de Janeiro: Campus, 1994.

NONAKA, I.; TAKEUCHI, H. Criação de conhecimento na empresa: como as empresas japonesas geram a dinâmica da inovação. Rio de Janeiro: Campus, 1997.

PÁDUA, S. I. D.; CAZARINI, E. W.; INAMASU, R. Y. Modelagem organizacional: captura dos requisitos organizacionais no desenvolvimento de sistemas de informação. Gestão \& Produção, v. 11, n. 2, p. 197-209, 2004.

PEREIRA, H. J. Proposição de um modelo organizacional baseado no conhecimento: um estudo de caso em empresa pública. In: Third International Conference of the Ibero-American Academy of Management. Anais ... São Paulo: 2003, v. 1, p. 1-15, CD-ROM. Disponível em: $<$ www.fgvsp.br/iberoamerican/Papers/0440_ Proposição 20 um Modelo Organizacional Baseado no Conhecimento>. Acesso em: jul. 2006.

PINHEIRO DE LIMA, E.; GOUVÊA DA COSTA, S.; PEREIRA, H. J.; FERRARESI, A. A.; BUSETTI DE PAULA, M. A. Diretrizes Estratégicas para a implantação da gestão do conhecimento organizacional. Produto \& Produção, v. 8, n. 2, p. 57-73, 2005.

PROBST, G.; RAUB, S.; ROMHART, K. Gestão do conhecimento: os elementos construtivos do sucesso. Porto Alegre: Bookman, 2002.

SANTOS, A. R.; PACHECO, F. F.; PEREIRA, H. J.; BASTOS JR., P. A. Gestão do conhecimento como modelo empresarial. In: (Ed.) Gestão do conhecimento: uma experiência para o sucesso empresarial. Curitiba: Champagnat, 2001. p. $11-48$ 
SILVA, S. L. Informação e competitividade: a contextualização da gestão do conhecimento nos processos organizacionais. Ciência da Informação, v. 31, n. 2, p. 142-151, 2002.

SMITH, A. D. Knowledge management strategies: a multi-case study. Journal of Knowledge Management, v. 8, n. 3, p. 6-16, 2004.
TERRA, J. C. C. Gestão do conhecimento: aspectos conceituais e estudo exploratório sobre as práticas de empresas brasileiras. Tese de Doutorado.Universidade de São Paulo, 1999.

TSAI, C. M. Integrating intra-firm and inter-firm knowledge diffusion into the knowledge diffusion model. Expert Systems with Applications. Disponível em: <www.elsevier.com/locate/ eswa>. Acesso em: maio 2007.
YEH, Y. J.; LAI, S. Q.; HO, C. T. Knowledge management enablers: a case study. Industrial Management \& Data Systems, v. 106, n. 6, p. 793-810, 2006.

YIN, R. K. Case study research: design and methods. Sage: Newburry Park, 1989.

\section{SOBRE OS AUTORES}

\section{Luciano Czermainski Gonçalves}

Programa de Pós-Graduação em Engenharia de Produção e Sistemas - PPGEPS

Pontifícia Universidade Católica do Paraná - PUCPR

End.: Rua Imaculada Conceição, 1155 - Curitiba - 80215-910

Tel.: (41) 3271-1333; Fax: (41) 3271-1345

E-mail: lucianoczer@gmail.com

\section{Edson Pinheiro de Lima}

Programa de Pós-Graduação em Engenharia de Produção e Sistemas - PPGEPS

Pontifícia Universidade Católica do Paraná - PUCPR

End.: Rua Imaculada Conceição, 1155 - Curitiba - 80215-910

Tel.: (41) 3271-1333; Fax: (41) 3271-1345

E-mail: e.pinheiro@pucpr.br

\section{Sérgio Eduardo Gouvêa da Costa}

Programa de Pós-Graduação em Engenharia de Produção e Sistemas - PPGEPS

Pontifícia Universidade Católica do Paraná - PUCPR

End.: Rua Imaculada Conceição, 1155 - Curitiba - 80215-910

Tel.: (41) 3271-1333; Fax: (41) 3271-1345

E-mail: s.gouvea@pucpr.br 